\title{
PEMODELAN PENGOLAHAN LIMBAH KERAJINAN JUMPUTAN PALEMBANG BERBASIS “GREEN SUPPLY CHAIN NETWORK”
}

\author{
Bunga Intan', M. Izman Herdiansyah², Diana ${ }^{3}$
}

\author{
Program Magister Teknik Informatika \\ ${ }^{1}$ STIMIK Musi Rawas, ${ }^{2,3}$ Universitas Bina Darma \\ email : bungaintan841@gmail.com,m.herdiansyah@binadarma.ac.id, \\ diana@binadarma.ac.id \\ Jl. A.YaniNo.12,Palembang30624,Indonesia
}

\begin{abstract}
The role of Green Suply Chain to a company or small and medium industries (IKM) such as the jump industry for environmental sustainability is very important especially in waste processing. One way that can be done is to make a model starting from raw materials obtained then processed to flow again to the user for the formation of an effective process flow called the process of Green Supply Chain Management. Model of Green Supply Chain Mangement waste processing industry waste cloth industry into clean water other than that with the model of Green Supply Chain Mangement can help the government in reducing the environmental damage caused by waste from the industrial waste jumputan. In this paper the research is in the area of craftsmen Mr Palembang Potato. We analyze and develop a model to improve performance in waste disposal processing in the jump industry industry with the main objective of optimizing or minimizing total cost in waste disposal processing.
\end{abstract}

Keywords: Palembang Jumputan Craft, Green Supply Chain Management, Network Optimization.

\begin{abstract}
Abstrak
Peranan Green Suply Chain terhadap suatu perusahaan ataupun industri kecil menengah (IKM) seperti industri kerajinan jumputan untuk keberlanjutan dalam aspek lingkungansangatlah penting terutama dalam pengolahan limbah. Salah satu cara yang dapat dilakukan adalah dengan membuat suatu model mulai dari bahan baku didapatkan kemudian diolah hingga dialirkan lagi ke pengguna agar terbentuknya suatu alur proses yang efektif yang disebut proses Green Supply Chain Management. Model Green Supply Chain Mangement pengolahan limbah industri pengrajin kain jumputan menjadi air bersih selain itu dengan adanya model Green Supply Chain Mangement dapat membantu pemerintah dalam mengurangi dampak kerusakan lingkungan yang diakibatkan dari limbah hasil industri kain jumputan. Dalam paper inipenelitian di kawasan pengerajin Tuan Kentang Palembang. Kami menganalisis dan mengembangkan sebuahmodel untuk meningkatkan kinerja dalam proses pengolahan
\end{abstract}


limbah jumputan di industri kerajinan jumputandengan tujuan utama yaitu mengoptimasi atau meminimumkan total biaya dalam proses pengolahan limbah jumputan.

Kata kunci : Kerajinan Jumputan Palembang, Green Supply Chain Management, Optimasi Jaringan.

\section{PENDAHULUAN}

Dengan kemajuan teknologi informasi saat ini yang terus berkembang membuat perusahaan atau badan usaha harus melakukan suatu inovasi yang tetap memperhatikan kualitas lingkungan untuk meningkatkan tingkat efisiensi kerja. Perkembangan industri tekstil khususnya Industri Kecil Menengah (IKM) di Sumatera Selatan saat ini mengalami kemajuan yang cukup pesat sehingga banyak menimbulkan dampak positif terhadap perekonomian masyarakat. Akan tetapi disamping dampak positif, kegiatan di bidang sandang ini juga memberikan dampak negatif terhadap lingkungan.

Chopra \& Meindl (2001) menyatakan bahwa dalam Supply Chain Managent (SCM) terdapat empat penggerak (driver), yaitu persediaan, transportasi, fasilitas, dan informasi. Dari keempat penggerak tersebut, informasi merupakan penggerak utama. Informasi sangat mempengaruhi ketiga penggerak lainnya. Peranan teknologi informasi di dalam supply chain sangat diperlukan untuk mendukung proses bisnis dan menunjang keberhasilan suatu industri karena dalam pengolahan data yang konvensional tidak cukup untuk mendukung proses bisnis yang maksimal perlu adanya dukungan dari teknologi informasi agar proses bisnis berjalan dengan cepat, tepat dan efisien.

Produksi Jumputan adalah kegiatan yang dilakukan untuk menambah nilai suatu barang dengan cara pembuatan motif pada kain dengan mengikat kain kemudian dimasukkan kedalam larutan zat warna sehingga terjadi reaksi antara serat kain dan zat warna. Dari proses pembuatan Jumputan inilah terdapat limbah industri Jumputan yang belum di manfaatkan oleh pihak Industri Kerajinan Jumputan sehingga mempengaruhi kualitas lingkungan di sekitar dan belum adanya sistem informasi untuk mendukung dalam proses pemanfaatan limbah. Seiring dengan kebutuhan manusia yang menginginkan kemudahan, kecepatan, dan keakuratan dalam memperoleh informasi. Oleh karena itu kemajuan teknologi informasi harus terus di upayakan dan ditingkatkan kualitas dan kuantitasnya. Salah satu kemajuan teknologi informasi ini di rasakan juga kegunaan dan manfaatnya dalam meningkatkan proses bisnis diperusahaan maupun Indusri Kecil Menengah (IKM), karena belum adanya pengaplikasian sistem informasi yang berbasis komputer di dalam pemanfaatan limbah industri Jumputan untuk itu saat ini Industri Jumputan membutuhkan sebuah sistem informasi yang disebut sistem informasi Bank Limbah yang digunakan untuk proses pengolahan informasi data yang dikhususkan dalam proses pencatatan data pemanfaatan limbah industri Jumputan yang terintegrasi secara menyeluruh untuk kemudahan, kecepatan, dan keakuratan dalam memperoleh informasi. karena suatu informasi dikatakan berguna dan berkualitas apabila didukung oleh tiga pilar, yaitu relevance (tepat pada orangnya), timeliness (tepat waktu), dan accurate (tepat nilainya), Jogiyanto (2003).

Penelitian yang akan dilakukan dalam menganalisis, membuat pemodelan dan merancang sistem informasi dalam pemanfaatan limbah industri Jumputan mengacu kepada suatu kerangka baru untuk mencapai keberlanjutan (sustainability) dalam aspek lingkungan yang disebut green supply chain karena selama ini wacana pemerintah untuk memperbaiki kualitas lingkungan di kawasan Tuan Kentang Kertapati belum terealisasi hingga saat ini.

Bentuk pemodelan green supply chain ke dalam sebuah sistem informasi dari pemanfaatan limbah yang akan di buat single point to multi object, dari green supply chain management yang akan di otimasikan dengan penciptaan rumus perhitungan matematis. 
Dampak pengoptimasian yang akan dilakukan, secara langsung akan menghasilkan aliran informasi yang tepat dan pengelolaan manajemen yang semakin baik. Dengan adanya optimasi jaringan maka perhitungan bahan baku Produk yang di hasilkan dan keuntungan dari pemanfaatan limbah Jumputan akan lebih teroptimasi sehingga hubungan dari tahapan green supply chain akan saling berterkaitan.

Berdasarkan permasalahan yang telah di uraikan di atas, penulis ingin menganalisis dan membuat pemodelan green supply chain ke dalam sebuah sistem informasi yang disebut sistem informasi Bank Limbah dalam pemanfaatan limbah industri Jumputan menggunakan model green supply chain pada Industri Jumputan Tuan Kentang.

\section{TINJAUAN PUSTAKA}

\subsection{Green supply chain Management}

Green supply chain Management Menurut Vachon and Klassen (2008), ketika suatu perusahaan berusaha untuk mencapai keberlanjutan (sustainability) dalam aspek lingkungan, manajemen harus memperluas usaha mereka untuk meningkatkan praktik yang berhubungan dengan lingkungan di sepanjang supply chain. Sabri dan Beamon (2000) menyatakan bahwa semua faktor yang mempengaruhi elemen khusus dalam suatu rantai (chain) akan diperpanjang ke rantai (chain) lainnya. Berdasarkan pendapat-pendapat tersebut dapat disimpulkan bahwa pada green supply chain management, penilaian proses internal (midstream) perusahaan harus digabungkan dengan proses eksternal (upstream dan midstream) yang melibatkan pemasok (supplier), agen penyalur barang (distributor) dan pelanggan (customer). Revolusi kualitas pada akhir tahun 1980 dan revolusi supply chain pada awal tahun 1990 telah memperjelas bahwa praktik terbaik memerlukan integrasikan pengelolaan lingkungan dengan aktivitas operasi yang dilakukan secara kontinu (Srivastava, 2007). Selain itu, permintaaan pasar global dan tekanan pemerintah mendorong bisnis menjadi lebih sustainable (Gungor dan Gupta, 1999). Hal ini mendorong banyak perusahaan untuk mengintegrasikan aspek ramah lingkungan (green) ke dalam supply chain. Green supply chain management dapat dinyatakan sebagai pembelian yang ramah lingkungan, proses manufaktur yang ramah lingkungan, pengelolaan material, distribusi dan pemasaran yang ramah lingkungan, dan reverse logistic (Linton et al., 2007; Zhu dan Sarkis, 2006, Srivastava, 2007). Perancangan Model Pengukuran....(H. saputra et al.)

1. Perancangan yang ramah lingkungan (green design) Perancangan produk yang ramah lingkungan merupakan perancangan produk atau jasa yang mendorong kesadaran lingkungan. Menurut Srivastava (2008), Ruang lingkup perancangan yang ramah lingkungan (green design) meliputi banyak disiplin, mencakup pengelolaan resiko lingkungan, keamanan produk, kesehatan dan keamanan yang berkaitan dengan pekerjaan, pencegahaan polusi, konservasi sumber daya, dan pngelolaan limbah.

2. Proses manufaktur yang ramah lingkungan (Green manufacture) Proses manufaktur yang ramah lingkungan yaitu proses manufaktur yang direncanakan dan dieksekusi dengan mengurangi resiko dan dampak negatif pada lingkungan. Menurut Srivastava (2006), proses manufaktur yang ramah lingkungan dapat dibagi pengurangan sumber daya (reducing), daur ulang (recycling), pemulihan product dan material (product and material

recovery), penggunaan kembali (reuse), pengelolaan persediaan (inventory management), dan perencanaan dan pengendalian produksi (production planning and schedulling).

3. Reverse logistic Kekhawatiran tentang isu lingkungan, pengembangan berkelanjutan, dan peraturan hukum yang sah membuat organisasi bertanggung jawab terhadap Reverse logistic (Srivastava dan Srivastava, 2006). Reverse logistic merupakan lawan dari traditional/forward logistic (Beamon, 1999). Memperpanjang supply chain dengan memasu- 
kan isu-isu seperti produksi kembali (rema-nufacturing process), daur ulang (recycling), dan pembaharuan kembali (refurbishing) menam-bahkan tingkat kerumitan pada rancangan supply chain yang telah ada sebagai tambahan untuk aturan baru menyangkut issu operasional dan strategi yang penting (Linton, et al., 2007).

4. Pengelolaan limbah (waste management) Pengelolaan limbah dilakukan untuk mengurangi limbah berbahaya agar tidak menimbulkan dampak buruk terhadap lingkungan. Menurut Srivastava (2006), Pengelolaan limbah mencakup kegiatan pengurangan sumber daya, pencegahan polusi, dan pembuangan. Menurut Salam (2008), manfaat penerapan green supply chainmanagement sebagai berikut:Peningkatan ekonomi melalui peningkatan efisiensi.

a. Keuntungan berkompetisi melalui inovasi.

b. Meningkatkan kualitas produk.

c. Memelihara konsistensi terhadap lingkungan.

d. Meningkatkan citra perusahaan.

e. Konservasi alam.

f. Pengurangan limbah.

g. Menghemat biaya.

h. Mengurangi jumlah zat-zat atau bahan berbahaya.

Green supply chain sangat penting untuk kesuksesan implementasi dari industrial ecosystem dan industrial ecology. Semua aktivitas di sepanjang supply chain memiliki resiko dan dampak negatif terhadap lingkungan. Menurut Beamon (2005), tujuan dari pengelolaan supply chain yang sadar lingkungan adalah mempertimbangkan dampak lingkungan akhir dan sekarang dari semua produk dan proses dalam rangka melindungi lingkungan alam.

\section{RANCANGAN MODEL “GREEN SUPLLY CHAIN" PENGLAHAN LIMBAH JUMPUTAN}

Adapun metode yang digunakan dalam penelitian ini yaitu metode development research.Menurut Supardi (2005:25), suatu kegiatan penelitian yang bertujuan dan berusaha mengembangkan atau melengkapi pengetahuan yang sudah ada atau diketahui. Permasalahan manusia dan lingkungan alamnya selalu berkembang yang kesemuanya ini harus memperoleh jawaban yang seimbang.

\subsection{Desain Penelitian}

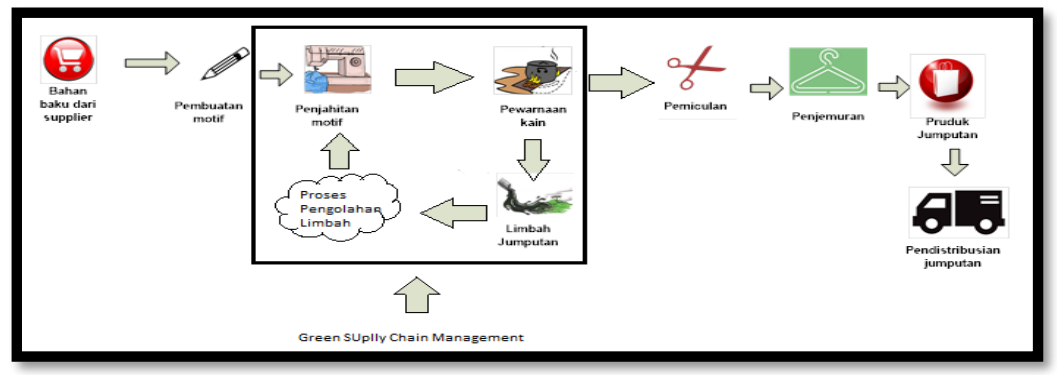

Gambar 2:Proses GSCM Pengolahan Limbah Jumputan 
Air limbah sebagai bahan sisa produksi kain Jumputan diproses oleh Bank Limbah agar air limbah yang sebelumnya hanya dibuang di sekitar kawasan pengrajin Jumputan dapat digunakan kembali sebagai bahan baku untuk proses pewarnaan kain Jumputan selanjutnya.

Model distribusi produksi air limbah jumputan yang telah dipelajari dapat dijelaskan pada Gambar 3.

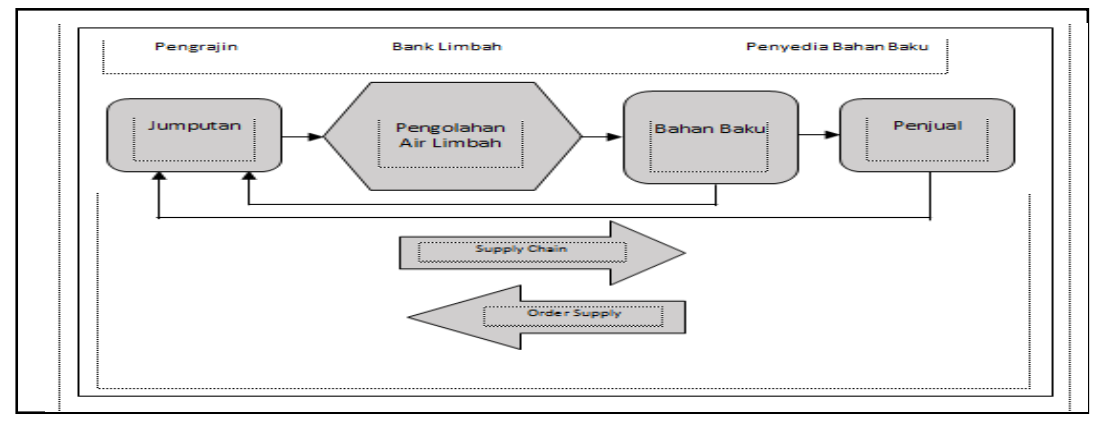

Gambar 3:Proses Alur Supplay Chain Pengolahan Limbah Jumputan.

Ada 2 kelompok yang terlibat dalam model distribusi produksi yaitu:

1. Pengrajin sebagai penyedia bahan baku yaitu air limbah bekas pencucian kain jumputan.

2. Bank limbah sebagai pengelolah air limbah menjadi air bersih

3. Pengrajin kain jumputan yaitu konsumen yang menggunakan air limbah yang telah di daur ulang.

\subsection{Model Optimasi}

Model optimasi digunakan untuk menghitung total biaya dalam proses pembuatan komponen Green Supply Chain Management (GSCM), yang berguna untuk mengetahui apakah komponen tersebut dapat berguna secara efektif dan efisien dalam proses produksi Kain Jumputan tersebut sehingga dapat menghemat angka produksi. Berikut macam-macam total biaya yang akan diperhitungkan dalam Green Supply Chain Management (GSCM):

1. Biaya Bahan Baku Limbah

2. Biaya Produksi

3. Kapasitas Quantity

4. Biaya Beban Per Bulan

5. Total Biaya

6. Keuntungan Bersih Bank Limbah

Faktor pembatas proses digunakan untuk membatasi jumlah proses limbah yang akan diolah agar jumlah proses tidak melebihi batas maksimum filterisasi oleh tabung filter, daya tampung kolam penampungan limbah dan kapasitas torrent yang digunakan untuk menampung hasil pengolahan limbah.

Proses filterisasi oleh tabung filter harus disesuaikan dengan kapasitas tabung. Tabung filter yang digunakan adalah tabung dengan kapasitas 500 liter/jam. Dalam satu periode (1 hari) tabung filter dapat memproses air limbah dengan jumlah 3,975 $\mathrm{m}^{3}$ (3975 liter). Sedangkan untuk daya tampung kolam yang berukuran $4 \times 4 \times 2$ meter adalah $32 \mathrm{~m}^{3}$ (32.000 liter). Dan untuk daya tampung torrent adalah $5 \mathrm{~m}^{3}$ (5.000 liter). Sehingga jumlah maksimum proses pengolahan limbah dalam satu periode yang dapat ditampung adalah $5 \mathrm{~m}^{3}$. Jadi dengan kata lain faktor pembatas proses ditentukan oleh besar torrent yang digunakan untuk menamping air bersih hasil pengolahan bahan baku limbah. 


\section{HASIL DAN PEMBAHASAN}

\subsection{Sistem Yang Dihasilkan}

Sistem Informasi Bank Limbah, pengolahan air limbah jumputan menjadi air bersih dengan pendekatan optimasi jaringan yang berhasildiimplementasikandiuji-coba pada lingkungan komputer tunggal yang telah dilengkapi dengan paket XAMPP (Apache, PHP dan $M y S Q L)$ dan web browser Firefox, Google Chrome. Pembahasan uji-coba menjalankan aplikasi disajikan berikut ini:

1. Tampilan Halaman Login

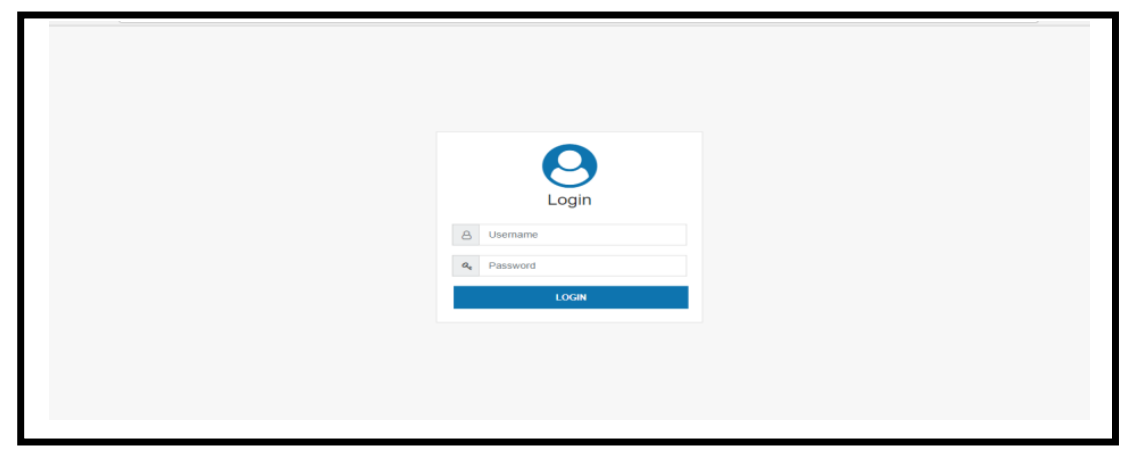

Gambar 4. Tampilan Halaman Login

2. Tampilan Halaman Penjualan Limbah

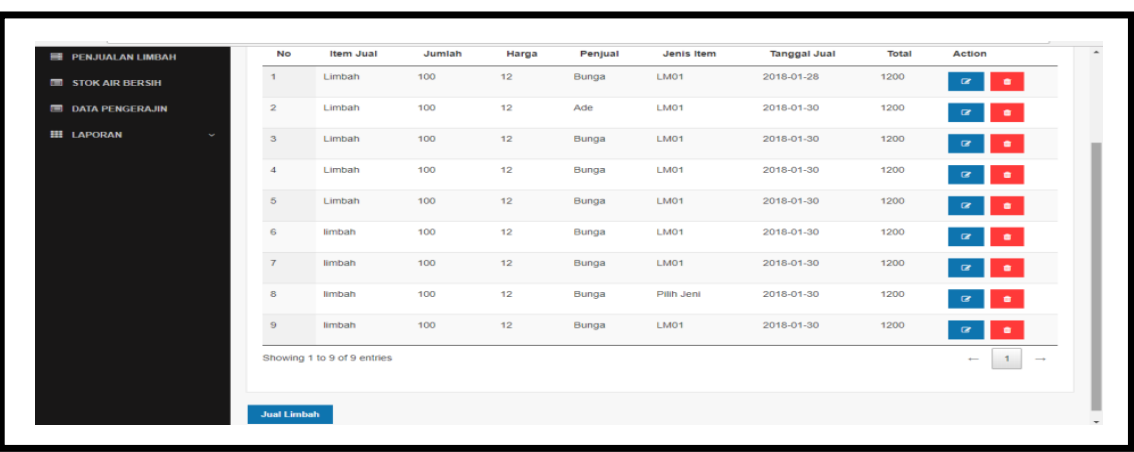

Gambar 5. Tampilan Halaman Penjualan Limbah

3. Tampilan Halaman Penjualan Air Bersih

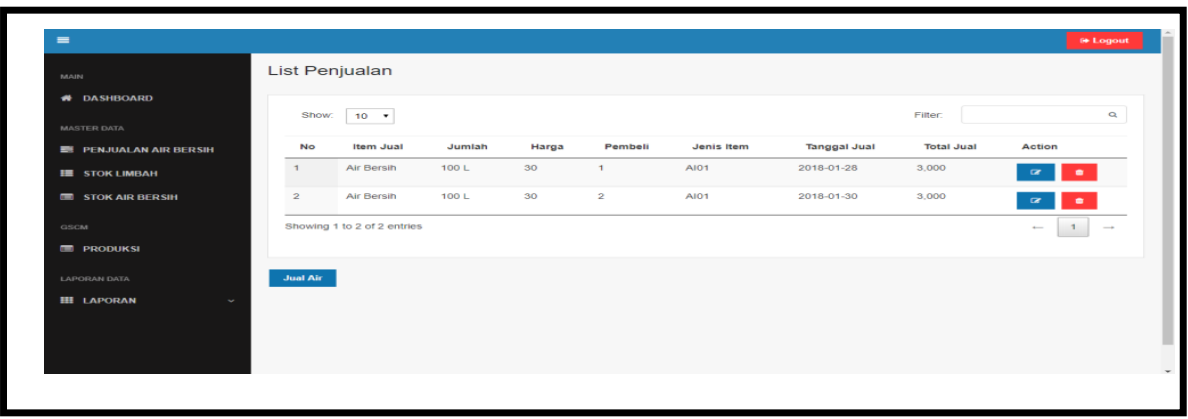

Gambar 6. Tampilan Halaman Penjualan Air Bersih 
4. Tampilan Data Produksi

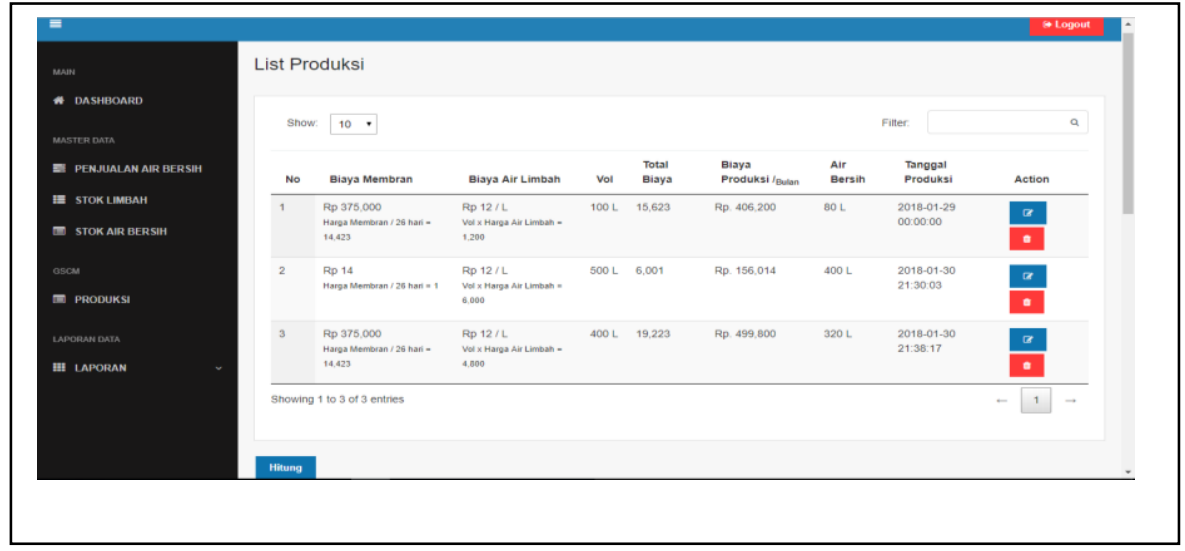

Gambar 7.Tampilan Data Produksi

\subsection{Pembahasan Optimasi Biaya Pengolahan GreenSupplay Chain Management}

Untuk mengetahui optimalisasi perhitungan total biaya meliputi biaya pembelian limbah, biaya pengolahan, serta peralatan, maka dapat dihitung dengan rumus yang telah dibuat. Dalam satu periode pengolahan limbah industri kain jumputan menjadi air bersih membutuhkan 1 (satu) hari untuk 5.000 liter air bersih. Dalam melakukan pengolahan dibutuhkan faktor pembatas diantaranya jeda pengolahan air bersih untuk menjaga kestabilan mesin pengolahan yaitu 2 (dua) jam/hari.

Berikut perhitungan total biaya (total cost) dalam satu priode pengolahan limbah menjadi air bersih:

\section{Biaya Bahan Baku}

Untuk menghitung total biaya penjualan limbah dari setiap pengrajin dalam setiap bulan adalah total jumlah limbah yang dihasilkan oleh pengrajin dalam satu hari dikalikan dengan harga limbah per liter dan dikalikan 26 hari kerja dalam satu bulan. Total biaya bahan baku limbah dapat dihitung menggunakan rumus dengan keterangan sebagai berikut :

$\mathbf{Q}_{\mathbf{l}}=$ Jumlah limbah

$$
=\sum\left(\mathbf{Q}_{\mathbf{l}} \times \mathbf{R p} 12\right)
$$

Rp 12 = Harga Air Limbah/Liter

$=\sum(100$ Literx Rp 12$)=$ Rp. 1200

Sehingga total biaya bahan baku limbah adalah Rp. 1200

2. Biaya Produksi

Untuk Menghitung biaya produksi air limbah kain jumputan dari setiap kali proses produksi dilakukan, biaya membran per/hari ditambahkan biaya dari penjualan limbah. biaya produksi dapat dihitung menggunakan rumus dengan keterangan sebagai berikut:

$$
\Sigma B_{p}=\Sigma B_{m}+\Sigma a l(2)
$$




\section{$\Sigma \mathbf{B}_{\mathbf{p}}$ = Total Biaya Produksi \\ $\Sigma \mathbf{B}_{\mathbf{m}}=$ Total Biaya Membran \\ $\Sigma$ al $=$ Total biaya air limbah}

Sehingga total biaya produksi yang dibutuhkan bank limbah dalam setiap bulannya adalah Rp 15.623.

Table 1:Estimasi Biaya Produksi

\begin{tabular}{cll}
\hline No & \multicolumn{1}{c}{ Item } & \multicolumn{1}{c}{ Biaya 1 bulan } \\
\hline 1 & Biaya membran & $\operatorname{Rp~14.423}$ \\
\hline 2 & Biaya air limbah & $\operatorname{Rp~1.200~}$ \\
\hline Total & & $\operatorname{Rp~15.623}$ \\
\hline
\end{tabular}

3. Biaya Air Bersih

Untuk menghitung total biaya pembelian air bersih setiap pengrajin dalam waktu satu bulan adalah total jumlah air bersih yang di beli oleh pengrajin dalam satu hari dikalikan dengan harga air bersih yang ditetapkan dan dikalikan 26 hari kerja dalam satu bulan. Total biaya biaya air bersih dapat dihitung menggunakan rumus dengan keterangan sebagai berikut :

$$
=\quad \sum\left(\mathbf{Q}_{1} \times \mathbf{R p} 30\right) \text {, }
$$

$\mathbf{Q}_{\mathrm{Ab}}=$ Jumlah Air Bersih

Rp 30 = Harga Air Bersih/Liter

100x Rp 30 = Rp. 3.000

Sehingga total biaya air bersih yang harus di keluarkan pengrajin adalah Rp. 3.000

\section{Kapasitas Quantity}

Untuk Menghitung kapasitas quantity atau hasil pengolahan air bersih dari limbah industri kain jumputan adalah $80 \%$. Dengan kata lain, hasil kapasitas quantity air bersih tidak sama dengan limbah yang diproses. Kapasitas quantity dapat di hitung menggunakan rumus.

Keterangan:

$$
\Sigma Q_{\mathrm{AB}}=80 \% \times \Sigma Q_{\mathrm{L}}
$$

$\Sigma \mathbf{Q}_{\mathrm{AB}}=$ Quantity Air Bersih

$\Sigma \mathbf{Q}_{\text {L }}=$ Quantity Limbah

Sehingga total air bersih yang diperoleh produksi adalah 80 Liter air.

5. Biaya Beban Per Bulan

Untuk menghitung biaya beban didapat dari biaya operasional, biaya operasional mencakup upah karyawan, bahan bakar minyak, servis kendaraan dan biaya listrik. Total biaya beban per bulan dapat dihitung menggunakan rumus.

$$
\Sigma B_{\mathrm{B}}=\Sigma \mathbf{G}_{\mathrm{K}}+\Sigma \mathrm{S}_{\mathrm{K}}+\Sigma \mathbf{B}_{\mathrm{K}}+\Sigma \mathbf{B}_{\mathrm{L}}
$$

$$
\begin{aligned}
& \text { Keterangan : } \\
& \boldsymbol{\Sigma} \mathbf{B}_{\mathbf{B}}=\text { Total Biaya Beban/Bulan } \\
& \boldsymbol{\Sigma} \mathbf{G}_{\mathbf{K}}=\text { Total Biaya Gaji Karyawan } \\
& \boldsymbol{\Sigma} \mathbf{S}_{\mathbf{K}}=\text { Total Biaya Servis Kendaraan } \\
& \boldsymbol{\Sigma} \mathbf{B}_{\mathbf{K}}=\text { Total Biaya BBM Kendaraan } \\
& \boldsymbol{\Sigma} \mathbf{B}_{\mathbf{I}}=\text { Total Biaya Listrik }
\end{aligned}
$$

Sehingga total biaya beban yang diperoleh dalam setiap bulan adalah Rp 4.100.000. 
Table 2: Estimasi Biaya Beban

\begin{tabular}{cll}
\hline No & \multicolumn{1}{c}{ Item } & \multicolumn{1}{c}{ Biaya 1 bulan } \\
\hline 1 & Gaji Karyawan $(3$ orang) & $\operatorname{Rp~3.000.000~}$ \\
\hline 2 & BBM kendaraan & $\operatorname{Rp~500.000~}$ \\
\hline 3 & Servis kendaraan & $\operatorname{Rp~} 100.000$ \\
\hline 5 & Biaya Listrik & $\operatorname{Rp~500.000~}$ \\
\hline Total & & $\operatorname{Rp~4.100.000}$ \\
\hline
\end{tabular}

6. Total Biaya

Untuk menghitung total biaya didapat dari total harga komponen peralatan pengolahan air limbah menjadi aiar bersih yang terdapat pada bank limbah. Total biaya mencakup komponen biaya pembuatan kolam, baiaya tabung filter, biaya torrent dan biaya instalasi, Total biaya komponen peralatan yang terdapat pada bank limbah dapat dihitung menggunakan rumus.

$$
\Sigma \mathbf{B}=\Sigma \mathbf{B}_{\mathrm{K}}+\Sigma \mathbf{B}_{\mathrm{TF}}+\Sigma \mathbf{B}_{\mathrm{T}}+\Sigma \mathbf{B}_{\mathrm{I}}
$$

Keterangan :

$\boldsymbol{\Sigma} \mathbf{B}=$ Total Biaya

$\Sigma \mathbf{B}_{\mathbf{K}}=$ Total Biaya Kolam

$\boldsymbol{\Sigma} \mathbf{B}_{\mathrm{TF}}=$ Total Biaya Tabung Filter

$\boldsymbol{\Sigma} \mathbf{B}_{\mathrm{T}}=$ Total Biaya Torrent

$\Sigma \mathbf{B}_{\mathbf{I}}=$ Total Biaya Instalasi

Sehingga total biaya atau modal pembuatan komponen peralatan yang harus dikeluarkan oleh bank limbah dalam proses pembuatan sistem pengolahan air limbah kain jumputan menjadi air bersih adalah $\mathrm{Rp} 20.860 .000$.

Table 3 : Total Biaya

\begin{tabular}{lll}
\hline No & \multicolumn{1}{c}{ Item } & \multicolumn{1}{c}{ Total } \\
\hline 1 & Biaya Kolam & Rp 11.375 .000 \\
\hline 2 & Biaya Tabung & Rp 3.000 .000 \\
\hline 3 & Biaya Torent & Rp 5.500 .000 \\
\hline 4 & Biaya Instalasi & Rp 985.000 \\
\hline Total & & Rp 20.860.000 \\
\hline
\end{tabular}

7. Biaya Air Pengrajin Per/Bulan

Biaya air pengrajin perbulan didapat dari total biaya pembelian air bersih per/bulan dikurangkan biaya biaya hasil penjualan air limbah per bulan Jika dihitung menggunakan rumus :

$$
\Sigma \mathbf{B}_{\text {ap }}=\left(\Sigma \mathbf{B}_{\mathrm{ab}}-\Sigma \mathbf{B}_{\mathrm{b}}\right)=
$$

Keterangan :

$\boldsymbol{\Sigma} \mathbf{B}_{\text {ap }}=$ Total Biaya Air Pengrajin

$\Sigma \mathbf{B}_{\text {ab }}=$ Total Biaya Air bersih

$\Sigma \mathbf{B}_{\mathbf{b}}=$ Total Biaya Bahan Baku

$\boldsymbol{\Sigma} \mathbf{B}=$ Total Beban

$\boldsymbol{\Sigma} \mathbf{B}_{\mathbf{b}}$ didapat dari harga limbah (Rp 12) dikali dengan jumlah pengrajin (100) dan jumlah hari kerja dalam satu bulan (26 hari). 
$\mathbf{H}_{\mathbf{L}}=$ Harga Limbah $(\mathrm{Rp} 12)$

$\Sigma \mathbf{A B}=$ Jumlah Air Bersih

$\Sigma B_{b}=12 \times 100 \times 26$

$\Sigma B_{b}=$ Rp $31.200 /$ bulan

Sedangkan untuk harga harga air bersih adalah:

$$
\Sigma B_{\mathrm{ab}}=\mathbf{H}_{\mathrm{AB}} \mathrm{X} \Sigma \mathrm{AB} \times \mathrm{H}_{\mathrm{K}}
$$

$\mathbf{H}_{\mathrm{AB}}=$ Harga Air Bersih / Liter

$\Sigma B_{\text {ab }}=\operatorname{Rp} 30 \times 100 \times 26$

$\Sigma B_{\text {ab }}=$ Rp 78.000 / bulan

Jadi total keseluruhan Biaya air bersih pengrajin per/bulan adalah:

Sehingga total biaya air yang harus dikeluarkan pengrajin jika pengrajin menggunakan air dari bank limbah biaya pengeluaran air mereka sebesar Rp. 46.800 sedangkan pengeluaran biaya air mereka perbulan jika menggunakan air PDAM biaya untuk pemakaian air yang harus dikeluakan pengrajin sebesar Rp. 150.000-Rp. 200.000 perbulan.

8. Keuntungan Bersih Bank Limbah

Keuntungan Bersih Bank Limbah didapat dari total biaya penjualan air bersih per/bulan sebanyak 100 pengrajin dikurangkan biaya bahan baku per bulan dan dikurangkan lagi dengan biaya beban per bulan Jika dihitung menggunakan rumus :

$$
\Sigma \mathbf{K}_{\mathbf{b}}=\left(\Sigma \mathbf{B a b}-\Sigma \mathbf{B}_{\mathbf{b}}\right)-\Sigma \mathbf{B}=(\mathbf{1 0})
$$

Keterangan :

$\boldsymbol{\Sigma} \mathbf{K}_{\mathbf{b}}=$ Total Keuntungan Bersih

$\boldsymbol{\Sigma} \mathbf{B}_{\mathbf{a b}}=$ Total Biaya Air bersih

$\boldsymbol{\Sigma} \mathbf{B}_{\mathbf{b}}=$ Total Biaya Bahan Baku

$\boldsymbol{\Sigma} \mathbf{B}=$ Total Beban

Sehingga total keuntungan bersih yang diperoleh pihak bank limbah dari hasil pengolahan air limbah menjadi air bersih dalam satu bulan adalah Rp. 580.000 setiap bulan.

Table 4 : Estimasi Keuntungan Bersih Bank Limbah

\begin{tabular}{lll}
\hline No & \multicolumn{1}{c}{ Item } & \multicolumn{1}{c}{ Total } \\
\hline 1 & Biaya air bersih/bulan & Rp 7.800.000 \\
\hline 2 & Biaya Bahan Baku/Bulan & Rp. 3.120.000 \\
\hline 2 & Biaya Beban & Rp 4.100.000 \\
\hline & Total & Rp. 580.000/Bulan \\
\hline
\end{tabular}

\subsection{Analisis konsep Green Supply Chain Management (GSCM)}

Dari proses pengolahan limbah atau daur ulang limbah yang dilakukan tentunya menghasilkan manfaat yang positif untuk pengrajin dan lingkungan. diantaranya sebagai berikut 


\section{Pengrajin}

Adapun maanfaat yang dirasakan oleh pengrajin dari proses daur ulang air limbah yaitu lingkungan di sekitar kawasan tempat tinggal mereka menjadi lebih bersih, mengurangi biaya air yang mana biasanya mereka harus mengeluarkan biaya yang cukup besar setiap bulan sekitar Rp. 150.000 sampai Rp. 200.000 untuk biaya pemakain air PDAM setiap bulanya, dan dengan adanya air hasil daur ulang air limbah menjadi air bersih yang dilakukan pihak bank limbah membuat pengrajin bisa lebih efektif dan efisien dalam proses produksi kain jumputan terutama pada proses pewarnaan kain. Karena saat ini beberapa titik rumah pengrajin di kawasan tersebut harus menunggu waktu tertentu untuk mendapatkan air bersih di sebabkan oleh air PDAM yang belum mengalir secara maksimal, sehingga dengan adanya air bersih dari proses daur ulang mereka berharap dapat melakukan pencucian kain kapan saja tanpa harus menunggu air PDAM mengalir.

2. Lingkungan

Dampak positif bagi lingkungan dari proses daur ulang air limbah menjadi air bersih adalah menciptakan lingkungan yang bersih dan sehat, karena kondisi lingkungan disekitar kawasan pengrajin saat ini cukup memprihatinkan saluran air yang ada di sekitar rumah warga menjadi kotor dan berbau, lingkungan di sekitarnya pun menjadi tidak teratur serta air rawa yang semula tidak terlalu kotor telah berubah menjadi warna yang sangat pekat dan kotor yang di sebabkan oleh air limbah buangan pengrajin di alirkan di saluran air dan pembuangan akhirnya di rawa tersebut. Dengan adanya bank limbah di harapkan air limbah tersebut dapat di manfaatkan secara maksimal dan sungai dan rawa yang ada di sekitar lingkungan terjaga.

\subsection{Bagian Model Green Supply Chain Management}

Terdapat tiga bagian penting dari model green supply chain management dalam pengolahan limbah jumputan mulai dari bagaimana air yang awalnya hanya di buang, bisa di tampung untuk selanjutnya dilakukan proses pengolahan dan dari pengolahan ini air yang dihasilkan bisa di manfaatkan kembali.

1. Pembuangan Limbah Cair

Saat ini para pengrajin hanya membuang limbah cair hasil produksi kain jumputan ke sungai dan daerah sekitar lokasi industri mereka. Dampak dari pembuangan limbah cair hasil produksi kain jumputan sangat buruk terhadap lingkungan. Lingkungan sekitar industri tersebut tercemar dan menimbulkan banyak kerugian bagi masyarakat dan lingkungan yang berada di daerah tersebut.

2. Proses Air Bersih Menjadi Limbah Cair

Proses air bersih menjadi limbah cair merupakan salah satu proses yang terdapat dalam pembuatan kain jumputan. Pada pengrajin jumputan Batiq Colet biasanya melakukan pembelian baku satu bulan sekali untuk produksi selama satu bulan kedepan. Produksi kain jumputan dilakukan seminggu sekali dengan menggunakan bahan baku kain sekitar 150 meter yang akan menghasilkan sekitar 50 potong kain dan maksimal dalam satu periode produksi pengrajin dapat menghasilsan 75 potong kain dengan ukuran 3 meter dengan menggunakan bahan baku lain dan pewarna setiap roduksi sekitar $2 \mathrm{~kg}$. Terkadang pengrajin juga memproduksi kain dengan ukuran 2 meter. Proses produksi dari pembuatan motif, penjahitan, pewarnaan, pelepasan tali, penjemuran, menjadi produk jumputan hingga pendistribusian produk.

3. Pengolahan Limbah Cair Menjadi Air Bersih

Pengolahan limbah cair hasil industri kain jumputan menjadi air bersih ditujukan agar limbah hasil produksi tersebut tidak mencemari lingkungan dan ekosistem disekitar. Proses pengolahan limbah tersebut menggunakan model Green Supply Chain Management (GSCM) 
yang mana model tersebut sangat membantu dan mempermudah proses pengolahan limbah menjadi air bersih.

\subsection{Analisis Sistem Bank Limbah}

Bank limbah aktifitas pengelolaan limbah dimana pengrajin (disebut sebagai nasabah) menjual air limbah dimana limbah yang dijual tersebut dapat di daur ulang kembali menjadi air bersih. Selanjutnya limbah yang dijual oleh nasabah ini akan dikonversi menjadi saldo pada setiap akun nasabah sesuai dengan harga yang telah di tetapkan. Berikut adalah jaringan Green Supply Chain limbah cair hasil pengolahan industry kain jumputan:

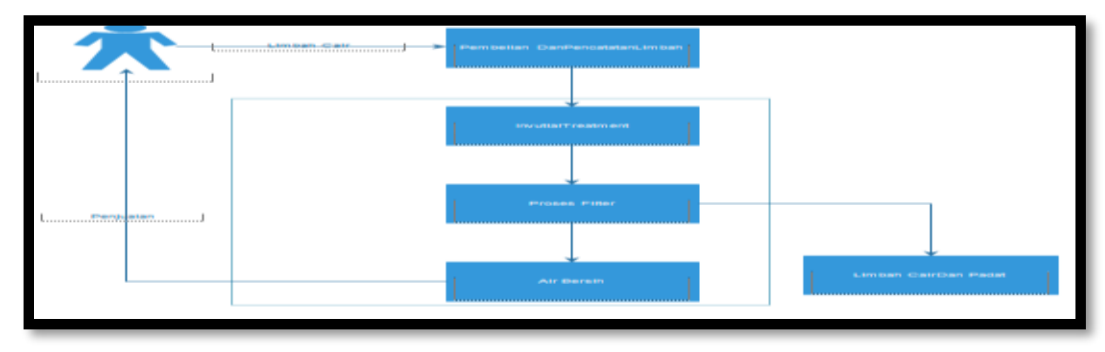

Gambar 4 :Analisis Sistem Bank Limbah

\subsection{Sistem Jaringan Green Supply Chain Management}

Sistem jaringan Green Supply Chain Management merupakan suatu jaringan yang membentuk sebuah sistem yang berfungsi sebagai pengirim informasi dari peralatan Green Supply Chain Management ke bank limbah. Data tersebut berupa data yang berisi tentang keadaan limbah dan air bersih yang diolah di dalam torrent.Berikut adalah gambar jaringan sistem Green Supply Chain Management:

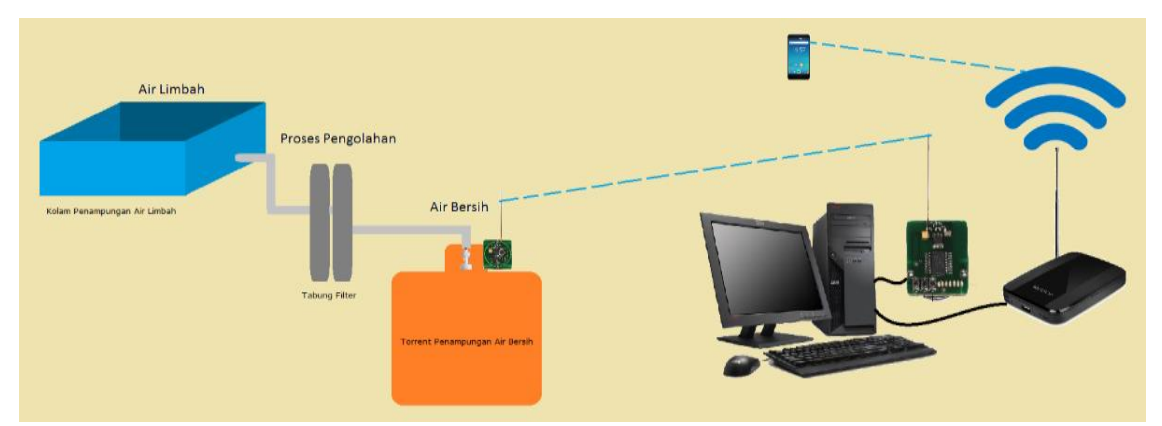

Gambar 5 : Sistem Jaringan Green Supply Chain Management

Pada gambar terdapat sebuah sensor pelampung yang dihubungkan ke Transmitter yang akan mengirimkan sinyal data ke Receiver yang dihubungkan ke PC. Receiver tersebut akan mengirimkan sinyal ke HP melalui wireless untuk menginformasikan data tentang air bersih yang ada dalam torrent.

Sensor pelampung tersebut berfungsi sebagai saklar otomatis mesin tabung filter. Data tersebut sangat berguna agar kinerja sistem jaringan peralatan tersebut dapat dipantau oleh bank limbah, apakah air bersih yang ada dalam torrent tersebut sudah penuh atau belum. 


\subsection{Sistem Informasi Bank Limbah}

Sistem informasi Bank Limbah merupakan sebuah sistem yang di bangun untuk mendukung kinerja karyawan Bank Limbah dalam proses pencatatan data proses pengolahan air limbah menjadi air bersih agar lebih efektif dan efisien. Sistem Informasi Bank Limbah mempunyai beberapa menu yang dapat digunakan oleh pengrajin dan admin bank limbah untuk melakukan proses penjualan limbah, penjualan air bersih, kas pengrajin, data produksi dan stok air limbah serta stok air bersih. Sistem informasi ini juga mempunyai laporan hasil penjualan maupun penjualan limbah dan air bersih. Laporan tersebut merupakan hasil rekapitulasi dari penjualan dan pembelian air bersih dan limbah. Hasil semua transaksi yang digunakan dalam system informasi ini juga merupakan hasil penjualan dan pembelian air bersih dan limbah.

Dengan adanya system informasi bank limbah ini sangat membantu para pengrajin dan bank limbah dalam transaksi. Sistem informasi ini juga dibuat sedemikian simple sehingga para pengrajin dapat dengan mudah mengerti dan mengoperasikan system tersebut.

Adapun tujuan dari system informasi bank limbah sebagai berikut:

1. Untuk membantu meningkatkan kualitas pelayanan danformasi organisasi yang baik sehingga dapat memberikan informasi secaraa kurat dan relevan.

2. Diharapkan dapat membantu bank limbah untuk mengelola proses manajemen internal mereka agar lebih tertata dan semakin profesional.

3. Adanya tranparansi dalam proses transaksi karena pengrajin dapat melihat akunya secara langsung.

\section{KESIMPULAN}

Kesimpulan yang dapat diambil dari hasil penelitian mengenai pengolahan limbah menjadi air bersih menggunakan pemodelan Green Supply Chain Management adalah sebagai berikut:

1. Model Green Supply Chain Mangement pengolahan limbah industri pengrajin kain jumputan menjadi air bersih.

2. Model Green Supply Chain Mangement dapat membantu pemerintah dalam mengurangi dampak kerusakan lingkungan yang diakibatkan dari limbah hasil industri kain jumputan.

3. Model Green Supply Chain Mangement dapat membantu pengrajin dalam menghemat air bersih dan menekan biaya pengeluaran pengrajin untuk kebutuhan air bersih.

4. Dalam penelitian ini menggunakan sebuah sistem informasi yang berguna untuk mempermudah pihak Bank Limbah dalam melakukan proses manajemen organisasi agar lebih baik dan efisien dalam pengolahan data dan melakukan pelayanan terhadap anggota Bank Limbah.

\section{Referensi}

Ardiyos, (2000). Kamus Besar Akuntansi. Citra Harta Firma, Jakarta

Arikunto, S. (2002). Metodologi penelitian. Penerbit PT. Rineka Cipta. Jakarta.

Beamon, B. M. (1999). Measuring supply chain performance. International journal of operations \& production management. 19(3), 275-292.

Beamon, B. M. (2005). Environmental and Sustainability Ethics in Supply Chain Management, Science and EngineeringEthics. vol 11, pp. 221-234.

Chopra, S., \& Meindl, P. (2001). Supplier Chain Management-Strategies, Planning, and Operation.

Jogiyanto, H. M. (2003). Teori portofolio dan analisis investasi. Yogyakarta 